\section{Sexta mesa de trabajo: procesos de recuperación de centros históricos en España}

El casco de nuestras ciudades ha de conservar su memoria histórica, encontrando el equilibrio adecuado entre lo nuevo y lo viejo, entre la renovación y la creación.

Las Administraciones Públicas competentes ha de actuar de forma coordinada y con la necesaria participación de todos los agentes y sectores involucrados, para conseguir una rehabilitación integral.

La rehabilitación real de un espacio urbano es imposible sin el esfuerzo en conjunto de "todos" los afectados, ya sean Administraciones o Administrados.

Tan importante es la recuperación de los valores arquitectónicos como urbanísticos, como también los aspectos culturales y sociales.

Es imposible plantear una rehabilitación sin entrar en el problema real que representa la vivienda.

El centro debe ser un espacio urbano tan vivo como el resto de la ciudad, en el que, además, las instalaciones y dotaciones deben responder a criterios del siglo XXI.
El centro no puede ni debe perder su carácter residencial, siendo necesario que los jóvenes vean el centro como lugar atractivo para vivir.

El estado de degradación de los centros históricos viene determinado por un mal endémico derivado de los problemas de abandono, envejecimiento de las viviendas y edificios, falta de equipamientos públicos y déficit de políticas de planeamiento. Ante esto hace falta preservación y, sobre todo, revitalización, por parte de los poderes públicos.

Hace falta una estrategia general y específica para los centros históricos: la recuperación de la vivienda sobre la base de recuperar el nivel de renta que permita la rehabilitación y la inversión pública que defina el marco de la intervención privada.

Hay que evitar el crecimiento hacia fuera de las ciudades, proponiendo como alternativa la reutilización y regeneración del propio casco antiguo.

A la hora de rehabilitar los centros históricos hay que redescubrir su policromía original y evitar unos centros históricos monocromáticos.

En áreas muy degradadas de centros históricos se precisan ayudas a fondo perdido para incentivar la rehabilitación.
En edificios religiosos que dan personalidad a los centros históricos se deben hacer intervenciones singulares sobre este patrimonio para dinamizar tanto el edificio como su entorno.

Dada la complejidad de la intervención sobre un centro histórico se hace necesario:

- Conocer el tejido social, arquitectónico, económico, etc. sobre el que se va a actuar

- Conocer la evolución histórica de la ciudad

- Programar en el tiempo un planeamiento adecuado

- Combinar adecuadamente la iniciativa pública y la privada.

- Realizar actuaciones integradas que afecten a todos los ámbitos.

- Fomentar la creación de redes de trabajo e intercambio de experiencias.

- Crear oficinas específicas de gestión.

- No esperar resultados inmediatos, los plazos de recuperación superan los 10 años.

El I Congreso de Centros Históricos de España, organizado por ARCHIVAL (Asociación para la Recuperación de los Centros Históricos de España), tuvo lugar en Madrid, durante los días 16 y 17 de octubre de 2001 .

\title{
Renovación urbana y reciclaje frente a consumo de suelo
}

La ciudad tradicional, básicamente compacta y bien delimitada respecto a su territorio, ha experimentado una fuerte expansión desde la revolución industrial que no sólo ha multiplicado ( $y$ en muchos casos sigue multiplicando) su población y su capacidad productiva sino también su extensión en el territorio. La ciudad de los inicios del s. XXI está así formada por tejidos históricos y ensanches, muchas veces núcleos históricos engullidos por la gran urbe, tejidos suburbanos, piezas de desarrollo asociadas a infraestructuras, asentamientos dispersos, espacios inciertos, espacios obsoletos... Sin embargo, el aumento de riqueza y el consumo exacerbado de recursos no ha aportado en el modelo actual una mejora de la calidad de vida de sus ciudadanos; aún así, la ciudad parece extenderse de forma indefinida sobre un territorio cada vez más amplio.
La urbanización masiva es un fenómeno global al que hay que dar nuevas respuestas, puesto que el actual modelo de crecimiento urbano es económica, política, social y ecológicamente insostenible. Es en este marco de urbanización desaforada en el que la IFHP ha propuesto su congreso, con el ánimo de analizar los problemas y proponer soluciones abordando a la vez las demandas de la nueva sociedad post-industrial. La renovación urbana se postula en la convocatoria del congreso como la alternativa sostenible al crecimiento urbano sin límite.

\section{Desarrollo del Congreso}

Participaron en el congreso 760 profesionales de ámbitos relacionados con lo urbano de 58 países. Se leyeron 20 ponencias referidas a zonas de todo el planeta; se presentaron 89 equipos de estudiantes de 24 países al concurso internacional; la escuela de verano de la IFHP, cuyo curso se desarrolló en la ETSAB (Escuela Técnica Superior de Arquitectura de Barcelona), contó con 45 estudiantes. El congreso se celebró en Barcelona entre el 9 y el 12 de Septiembre; tras la ceremonia inaugural, celebrada el domingo 9, se analizaron en los tres días consecutivos los componentes sociales y culturales de la renovación urbana, los factores operativos y la relación de la renovación urbana con el territorio.

En la ceremonia inaugural, presidida por el Excmo. Sr. Alcalde de Barcelona Joan Clos, el arquitecto Richard Rogers afirmó que las ciudades de la nueva era deben fundarse en el respeto medioambiental, el uso sostenible de los recursos y la mejora de la calidad de vida. 


\section{Noticias y Comentarios}

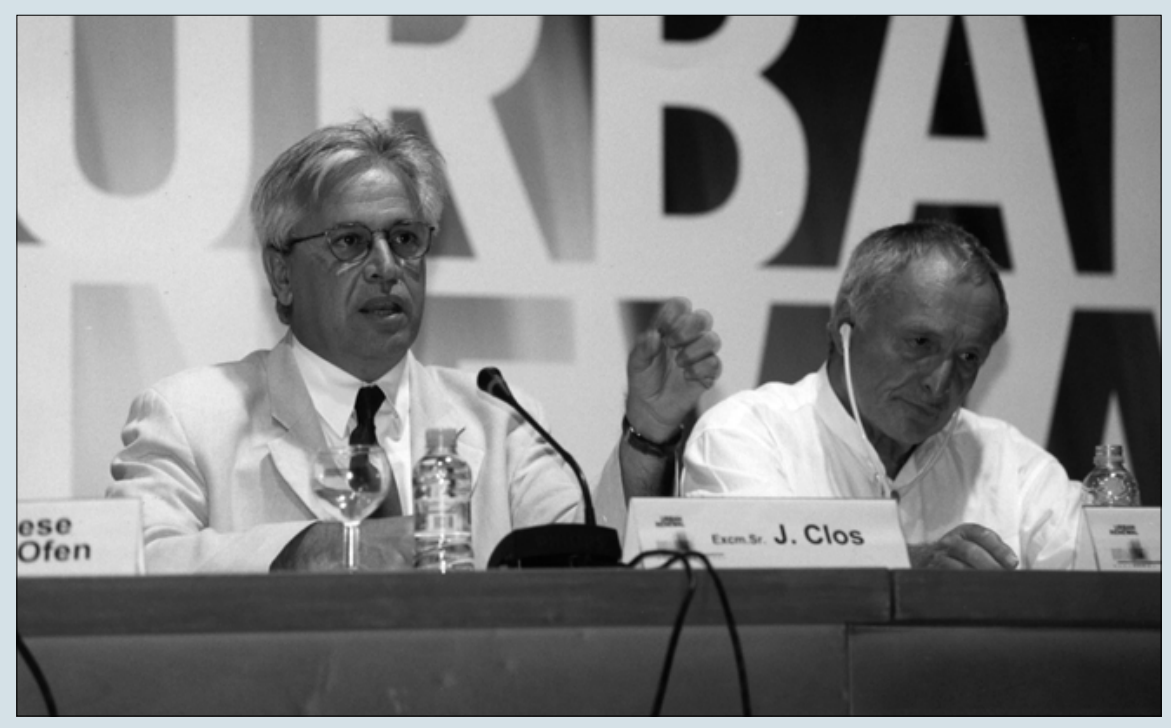

Apoyándose en su amplia experiencia en renovación urbana llevada a cabo en el Reino Unido, presentó los que a su juicio deben ser los principios físicos y políticos de la ciudad sostenible: compacidad, forma policéntrica, diversidad y mezcla de actividades y clases sociales, conectividad, actitud ecológica, buen diseño y fortaleza económica. No se puede construir la ciudad sostenible sin renovar las partes que por factores operativos, culturales, productivos o ambientales se han visto abandonadas o degradadas. Por ello, en la transformación de las ciudades la renovación urbana debe primar sobre la dispersión.

En lunes 10, se reflexionó sobre los componentes sociales y culturales en la renovación urbana. Si bien siempre existen elementos históricos, culturales, sociales y territoriales a valorar en cualquier extensión urbana, estos factores cobran mayor valor en la renovación urbana. Aún cuando la transformación de las ciudades es un proceso continuo e irreversible, es fundamental saber entender cuáles son los componentes intrínsecos que determinan el carácter de cada ciudad para conservarlos y, en su caso, potenciarlos. La identidad de la ciudad no es sólo la de su soporte físico, también lo son sus habitantes y las actividades que en ello se desarrollan. Por ello las intervenciones que en ella se realicen deben prestar especial cuidado en mantener la autenticidad de la ciudad- y no solamente en mantener o en embellecer su "fachada". Las ponencias presentadas, referidas a Barcelona (J. Busquets), Roma (D. Cecchini) y las ciudades históricas de Asia (M. Yang) ejemplificaron la complejidad de la identidad de las ciudades, las tensiones en la transformación que en ellas se presentan y las interven- ciones que se han realizado en el ánimo de una conservación no banal.

En martes II, el tema central fue los factores operativos en la renovación urbana. Tres ejemplos diversos- Barcelona (J.A. Acebillo), EE.UU.(N. Krumholz) y China (A. Coombes)- sirvieron para explicar quién y cómo se desarrolla la renovación urbana y cuáles son sus resultados. Se puso de relieve la importancia de que los operadores públicos tomen las riendas en las operaciones de renovación urbana para conseguir los propósitos de la ciudad sostenible- y la poca importancia que a tales propósitos otorgan hoy por hoy los operadores privados; se concluyó que del necesario equilibrio entre operadores privados y públicos depende que la ciudad pueda alcanzar la sostenibilidad en todos sus componentes: económico, social y ambiental.

Por último, el miércoles 12 se abordó la cuestión de la renovación urbana y el territorio. La extensión en el territorio de la ciudad, cada vez más vasta e informe es un hecho incuestionable; con ello la ciudad amplía las posibilidades de atraer nuevas inversiones e infraestructuras pero a su vez necesita cada vez más recursos para su funcionamiento sin aportar una mayor calidad de vida. La ciudad se dispersa pero también se disgrega y aún se segrega, siendo cada vez menos eficiente funcionalmente, menos solidaria socialmente, menos gobernable políticamente y menos sostenible ecológicamente. La ciudad crece sin identidad, siendo abandonado o degradado aquello que, sin haber sido nunca apreciado, deja de ser útil. En el ánimo de corregir tales tendencias, pero entendien- do que los fenómenos de metropolitanización y globalización son inevitables y aún en muchos casos positivos, la ciudad debe convertirse en una red de ciudades juiciosamente compactas y eficientes, donde la naturaleza y el espacio público jueguen un papel fundamental. Los ejemplos presentados fueron las áreas metropolitanas de Barcelona (O. Nel·lo),la cuenca del Rühr (K. Ganser) y Río de Janeiro ( $V$. Andreatta), dónde se han realizado y se planean numerosas operaciones de mejora y transformación de la ciudad construida.

\section{Conclusiones}

I. Constatamos que en un mundo dominado por los flujos no deja de crecer la importancia de los lugares como expresión de identidades fundadas en sus valores propios y diferenciadores. Ésta es la razón fundamental que refuerza nuestra confianza en el futuro de las ciudades. Éstas seguirán siendo centros de cultura y de actividad económica, y deberían seguir siendo también espacios de convivencia y solidaridad.

2. Es necesario moderar los procesos de extensión de las ciudades que a menudo ocupan territorios de gran valor natural o productivo. Por otro lado, la dispersión urbana suele generar una ciudad socialmente segregada y ambientalmente insostenible. En lo posible, el desarrollo de las áreas urbanas debería producirse hacia dentro, mediante la renovación de sus tejidos que facilite un uso más eficiente de los mismos.

3. La renovación urbana debe tender a un modelo de ciudad razonablemente compacta, con densidad suficiente para propiciar el tono urbano que facilita las oportunidades de transmisión de información, y contribuye también a una diferenciación clara con el espacio rural evitando la intrusión de lo suburbano en el paisaje abierto y la naturaleza.

4. El medio urbano se enriquece por la coexistencia de usos de muy diverso carácter con la vivienda, uso urbano fundamental. Con este criterio hay que pensar en nuevos usos y actividades, en especial los propios de la llamada nueva economía, que pueden aprovechar las ventajas que proporcionan el emplazamiento y la morfología de las áreas a renovar.

5. La renovación urbana debe plantearse con criterios de equidad, de modo que sus bene- 
ficios alcancen al mayor número de los ciudadanos y en especial a los residentes en las áreas afectadas más desfavorecidos económicamente. Actuaciones básicas en la recalificación de muchos centros históricos serán la atenuación de la pobreza, la mejora de la vivienda y las actividades de desarrollo social.

6. La historia de la ciudad que se manifiesta en sus edificios y en la configuración de los tejidos urbanos debe ser un componente básico de los proyectos de renovación. La ciudad debe desarrollarse en paz con su historia, bien entendido que la protección del legado histórico requiere a menudo intervenir y modificar sus elementos.

7. Es importante el papel de la iniciativa privada en los procesos de renovación urbana, aunque en cualquier caso será insustituible la dirección del sector público para definir una estrategia general a escala de ciudad, velar por la equidad de los procesos de renovación y abordar aquellas acciones necesarias que no pueden ser asumidas por los operadores privados.

8. Una de las claves del éxito de las políticas de renovación es acertar en las soluciones para la accesibilidad y la movilidad en tramas urbanas densas. A este respecto cabe señalar la idoneidad de estas tramas para ser dotadas de transporte público y para los modos ligeros de desplazamiento (bicicleta, a pie,...).

La recuperación de los tejidos históricos es incompatible con el uso indiscriminado del automóvil.

9. La recuperación de la calidad del paisaje es un instrumento de renovación eficaz a todas las escalas. En el medio urbano por la mejora de los espacios públicos y de la imagen de la edificación, en el territorio por la recuperación de unas relaciones cordiales entre naturaleza y ciudad, así como por la aportación de nuevos significados a aquellas implantaciones que perdieron, con el tiempo, su sentido.

10. Una planificación democrática y con sentido estratégico es imprescindible para la equidad social y la eficacia de los procesos de renovación. Asimismo una autoridad con suficiente amplitud de campo de acción es necesaria para abordarla a la escala territorial que requiere su enfoque desde criterios de sostenibilidad.

Milde Poncelas

Urban Renewal - Congreso anual de la IFHP

El Congreso de la IFHP tuvo lugar entre el 9 y el 12 de septiembre de 200 I en Barcelona.

\section{Éxito de participación en el I Congreso Iberoamericano de Patrimonio Cultural}

Más de ciento cincuenta especialistas de diversas áreas relacionadas con el patrimonio cultural, entre conferenciantes, participantes en mesas redondas, seminarios, jornadas y autores de comunicaciones se han encontrado en Madrid, entre los días 29, 30 de noviembre y I de diciembre, en el I Congreso Iberoamericano de Patrimonio Cultural.

El evento científico-técnico, auspiciado por la revista R\&R-Restauración y Rehabilitación, y organizado por la Asociación Española de
Gestores de Patrimonio Cutural, ha girado en torno a dos grandes cuestiones: la cooperación internacional en materia de patrimonio y una evaluación y prospectiva del sector en el año 2001.

Paralelamente, se han desarrollado el I Salón Europeo del Arte de la Restauración y la I Conferencia General de la Red Iberoamericana de Patrimonio Cultural.

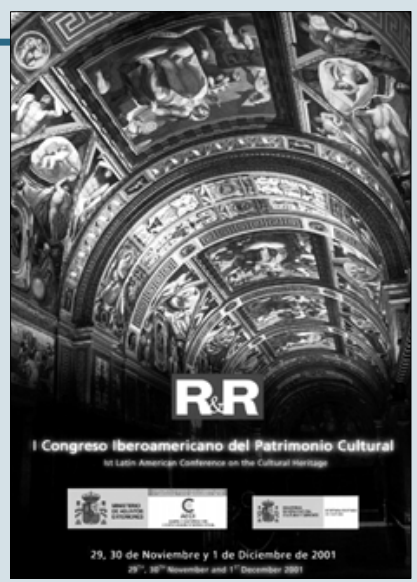

\section{En torno a Cano en la Casa de los Pisa}

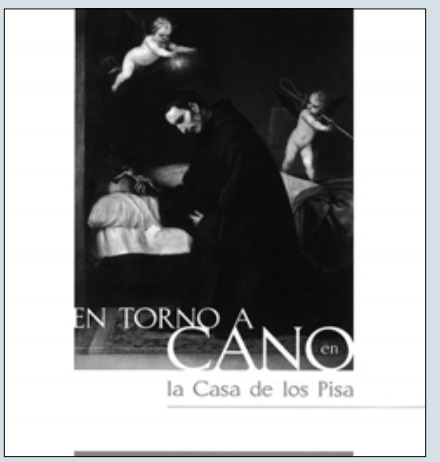

El Archivo-Museo de San Juan de Dios (Granada) se ha sumado a los actos conmemorativos del centenario del artista granadino Alonso Cano con una exposición encaminada a presentar su entorno artístico y su relación con la Orden Hospitalaria, reflejada en la pintura titulada Muerte de San Juan de Dios.

La vinculación artística de Cano con San Juan de Dios, quien murió cincuenta y un años antes del nacimiento del pintor $y$ escultor, surge entre 1652 y 1657 , período en el que esculpió la famosa ca- beza del Santo del Museo de Bellas Artes de Granada, y continúa con el cuadro antes citado. El lienzo, que debió ser pintado durante la primera etapa granadina de Cano, representa el momento en que San Juan de Dios murió abrazado a un crucifijo.

Los contenidos de la muestra, que tuvo lugar en la Casa de los Pisa entre el 5 de octubre y el 9 de noviembre de 200 I se recogen en el catálogo que ilustra esta nota. 